\title{
Condição de moradia dos domicílios urbanos nos municípios da Amazônia Legal segundo redes infraestruturais (2000 e 2010)
}

\section{Housing conditions of urban domiciles in the municipalities of the Brazilian Amazon according standards of infrastructural provision (2000 and 2010)}

Maurílio de Abreu Monteiro - Doutor em Desenvolvimento Sustentável do Trópico Úmido, pela Universidade Federal do Pará (UFPA). Pesquisador e professor titular da Universidade Federal do Sul e Sudeste do Pará (Unifesspa).E-mail: maurilio.monteiro@ unifesspa.edu.br

José Júlio Ferreira Lima - Doutor em Arquitetura, pela Oxford Brookes University (OBU), Grã-Bretanha. Pesquisador e professor da Universidade Federal do Pará (UFPA). E-mail: jjlima@ufpa.br

Adejard Gaia Cruz - Doutor em Economia, pela Universidade Federal do Pará (UFPA). Técnico em Gestão Pública da Secretaria de Ciência, Tecnologia e Educação Profissional e Tecnológica do Estado do Pará (SECTET). E-mail: adejardgaia@gmail.com

\section{Resumo}

O trabalho analisa padrões de abastecimento de água, de esgotamento sanitário e de energia elétrica nos domicílios urbanos dos municípios da Amazônia Legal. A metodologia empregada consiste na aplicação de índices de análise regional a partir de uma análise exploratória do universo de dados dos Censos Demográficos de 2000 e 2010, com foco na localização, na concentração e na conectividade das redes infraestruturais. Os resultados mostram que mais de $80 \%$ dos domicílios urbanos da região não eram providos com serviços básicos adequados e que, nos períodos intercensitários, não houve melhoria relativa substancial da posição regional em relação à média brasileira. A precariedade nos padrões das redes leva a uma baixa conectividade, constatando-se concentrações de domicílios urbanos por tipo de atendimento de um, de dois ou dos três serviços. Ao final, defendese a necessidade de uma gestão integrada com controle social para a melhoria nos padrões de provisão de redes infraestruturais.

\section{Palavra-chave}

Informações Censitárias. Índices de Provisão de Infraestrutura. Condições de Moradia. Amazônia.

\begin{abstract}
The papers analyses water supply standards, sanitation and electricity in urban dwellings of municipalities in the Legal Amazon. The methodology consists of analyzing regional indices: exploratory analysis of data universe of the Demographic Census of 2000 and 2010, location, concentration and connectivity of infrastructure networks. The results show that in the period, over $80 \%$ of urban households in the region were not provided with adequate basic services, and there is no substantial relative improvement from Amazon's position in relation to the Brazilian average. On provisioning, precariousness patterns of networks lead to low connectivity to the extent that urban households reveal concentrations by type of one, two or three services. Finally, it is argued the need for an integrated management with social control for the improvement of infrastructure conditions.
\end{abstract}

\section{Keywords}

Census Data. Indices of Infrastructure Provision. Dwelling Conditions. Amazon. 


\section{INTRODUÇÃO}

A urbanização acelerada no país nas últimas décadas, com o surgimento de novas expressões urbanas, tem ampliado as deficiências e o quadro de desigualdades econômicas e sociais. As disparidades, visíveis, em termos físicos, nas condições de moradia dos domićlios, devem-se à falta de infraestrutura, que configura o padrão de urbanização nacional, impondo grandes desafios ao poder público e à sociedade. As transformações econômicas, sociais, políticas e demográficas no Brasil, desde o início do século XX, não apenas impulsionaram o processo de urbanização como também revelaram a configuração de uma população socialmente desigual e distribuída em espaços econômicos concentrados, notadamente nas regiões Sul e Sudeste do país (CANO, 2007; BRITO; PINHO, 2012).

Ao focar as cidades da Amazônia Legal ${ }^{1}$, este artigo tem como objetivo analisar o padrão territorial das condições de moradia dos domicílios urbanos nos municípios da Amazônia Legal, fazendo uso de índices de análise regional, construídos com base em informações censitárias dos anos de 2000 e de 2010. Busca-se dialogar por meio de seus resultados com aspectos da complexa urbanização na região. As cidades na região são testemunhas de estratégias desagregadoras ligadas ao aproveitamento econômico a partir de forças exógenas contrárias a um ordenamento territorial coerente às práticas sociais $\mathrm{e}$ ao meio ambiente amazônico (BECKER, 2003). As complexidades intraurbanas estão ligadas ao processo de homogeneização, modernização e instalação do aparelho do Estado em intensidades que dependem dos surtos econômicos. As transformações, via de regra, inviabilizaram formas autóctones e produziram uma variedade de formas de ocupação urbana, da grande metrópole aos povoados, passando pelas cidades-empresa (TRINDADE JÚNIOR, 2010). As tipologias de cidades têm complexidades associadas ao relevo da várzea à terra firme. A variação de condições de urbanização quanto a infraestrutura está associada ao embate travado entre o endógeno e o atendimento das condições de exploração econômica da região por grandes projetos de produção de energia hidrelétrica e exploração mineral (CASTRO, 2008).

Merece destaque como referência fundamental para qualquer estudo que inclua dados referentes ao saneamento básico no Brasil, a análise situacional das condições do saneamento básico no país, incluindo a caracterização do déficit

\footnotetext{
Utiliza-se a regionalização da Lei Federal nº 5.173, de 27.10.1966 (BRASIL, 1966), pela sua extensão geográfica, que possibilita uma abrangência maior de municípios, bem como o estudo pode contribuir para análises mais abrangentes de políticas públicas, em uma perspectiva temporal ampla da ocupação urbana na Amazônia Legal.
} 
no acesso aos serviços, análise dos programas existentes e avaliação políticoinstitucional do setor; parte componente do Panorama do Saneamento Básico no Brasil publicado pelo então Ministério das Cidades (BRASIL, 2014). Nele, o esforço de compreensão das dimensões que compõem o Plano Nacional de Saneamento Básico (Plansab), em cumprimento à determinação da Lei no 11.445 , de 2007 (BRASIL, 2007), que estabeleceu as diretrizes nacionais e a política federal de Saneamento Básico, em suas quatro dimensões: abastecimento de água; esgotamento sanitário; manejo de resíduos sólidos (limpeza urbana e coleta de lixo) e; manejo de águas pluviais (drenagem urbana). O estudo compreende um diagnóstico histórico e transversal da situação do acesso da população ao saneamento básico e das políticas praticadas e apresenta avaliações prospectivas. Trabalha com o conceito da sustentabilidade dos serviços, no sentido de que não basta vislumbrar as necessidades de ampliação do acesso da população a estes, mas também se deve preocupar fortemente com a sua continuidade e a sustentabilidade econômica, cultural e ambiental.

Assim, este estudo, ao utilizar dados públicos, propõe uma opção metodológica compatível com a do Panorama e de outros estudos. Mantemse como base para este estudo os mesmos princípios fundamentais. Busca-se contribuir principalmente, sem detrimento dos demais ligados à gestão e ao financiamento, para alcançar a universalização do acesso, integralidade, articulação intersetorial, integração das infraestruturas e serviços entre si e com as políticas de desenvolvimento urbano e regional, de habitação, de combate à pobreza, de proteção ambiental e de promoção da saúde. Ao focar nos municípios da Amazônia Legal busca ainda reunir informações que possam levar à adoção de métodos, técnicas e processos que considerem as peculiaridades locais e regionais.

O procedimento metodológico adotado permite analisar, por meio dos índices, as condições dos municípios amazônicos em relação à concentração e à dispersão da ocorrência, da localização e da conectividade de redes infraestruturais nos espaços urbanos. Com o fito de apreender tais diferenciações, organizou-se o estudo em quatro seções, incluindo esta breve introdução. $\mathrm{Na}$ segunda, faz-se uma breve discussão teórica da problemática da urbanização e da questão da provisão de infraestrutura básica no Brasil. Na terceira seção, apresentam-se os procedimentos metodológicos e as bases de dados utilizados. A quarta seção traz os resultados e as evidências empíricas das análises por índices, comparandose a situação dos municípios da Amazônia e do Brasil. Por fim, seguem-se considerações finais. 


\section{ADEQUAÇÃO E PRECARIEDADE DE SERVIÇOS BÁSICOS DE INFRAESTRUTURA URBANA}

Ao analisar a expansão da infraestrutura de água e esgoto no território brasileiro na última década, com base em dados dos Censos Demográficos 2000 e 2010, Kleiman (2015) constata a persistência de assimetrias regionais, no qual os serviços básicos concentram-se principalmente na região Sudeste e em suas metrópoles, mantendo concomitantemente uma dispersão por cidades e metrópoles de outras regiões. Essa persistência tem fundamentos históricos no movimento de industrialização da economia nacional e sua concentração espacial, cuja dinâmica não apenas acelerou e concentrou o processo de urbanização, como também acentuou as desigualdades sociais e os desequilíbrios regionais.

Nesse sentido, uma das características marcantes do padrão de estruturação urbana das cidades brasileiras consiste na diferenciação acentuada na alocação e acesso aos serviços básicos prestados pelas redes de infraestrutura, com forte tendência a generalização de cobertura de serviços em concentrações urbanas (KLEIMAN, 2015). Uma das maiores expressões das desigualdades sociais e regionais refere-se ao atendimento das condições domiciliares, mormente por meio de serviços básicos de infraestrutura, tais como acesso a rede de esgotamento sanitário, rede de abastecimento de água, coleta de lixo, além do fornecimento de energia elétrica, serviço que se excetua do grupo saneamento, mas aqui incluído por ser prestado em rede como os demais. Por outro lado, apesar de ser importante, não se incluiu coleta de lixo por ser prestado por rede não exclusiva como as demais. Com essa configuração, "a localização específica de concentrações privilegiadas de quantidade e qualidade de serviços no espaço urbano define quem são e onde ficam os incluídos na cidade moderna" (SILVA, 2015, p. 407). Nessa ótica, o mesmo autor defende o uso da avaliação de conectividade dos serviços prestados em rede como instrumento de controle social, uma vez que considera que os conceitos de universalidade e cobertura, tradicionalmente utilizados na avaliação da infraestrutura urbana, não seriam mais suficientes para representar a complexidade da forma e da governabilidade urbana.

As pesquisas conduzidas pelo IBGE acerca do acesso aos serviços básicos de infraestrutura nas cidades brasileiras incluem o acesso a padrões de adequação e precariedade dos serviços de abastecimento de água; existência de tratamento e destinação de esgotamento sanitário e fornecimento de energia elétrica. Assim, os atributos dos Censos Demográficos do IBGE, anos 2000 (IBGE, 2002) e 2010 (IBGE, 2012), foram utilizados para a análise de padrões regionais da cobertura dos serviços em função do mapeamento e qualificação das três 
variáveis selecionadas e seus atributos. Tais dados, embora não tenham a mesma profundidade e atualidade da Pesquisa Nacional de Saneamento Básico (PNSB), do IBGE (IBGE, 2008), trazem indicações que permitem análises que podem contribuir para as discussões que são travadas no setor, em especial na direção do que é apontado pelo Panorama do Saneamento no Brasil.

No Quadro 1, as variáveis escolhidas (abastecimento de água; esgotamento sanitário e energia elétrica) são relacionadas a categorias de análise segundo os Censos Demográficos 2000 e 2010. Nele são sugeridas as análises da prestação dos serviços de forma isolada ou em conjunto associadas a condições de adequação e precariedade. $\mathrm{O}$ abastecimento de água e o esgoto sanitário seriam complementares, embora a ocorrência do segundo só possa ocorrer onde existe abastecimento de água por rede. Já o fornecimento de energia elétrica é menos dependente.

Quadro 1 - Atributos para construção de padrões de acesso a infraestrutura: variáveis abastecimento de água, esgotamento sanitário e abastecimento de energia elétrica quanto à adequação e precariedade, Censos Demográficos 2000 e 2010

\begin{tabular}{|c|c|c|c|c|}
\hline \multirow{2}{*}{$\begin{array}{l}\text { Descrição } \\
\text { da variável }\end{array}$} & \multicolumn{4}{|c|}{ Padrão e acesso a infraestrutura } \\
\hline & Adequado & $\begin{array}{l}\text { Inade- } \\
\text { quado }\end{array}$ & Precário & $\begin{array}{c}\text { Inexis- } \\
\text { tente }\end{array}$ \\
\hline $\begin{array}{l}\text { Abasteci- } \\
\text { mento de } \\
\text { água }\end{array}$ & 1- Rede geral & $\begin{array}{l}\text { 2- Poço ou } \\
\text { nascente } \\
\text { (na pro- } \\
\text { priedade) }\end{array}$ & $\begin{array}{l}\text { 3- Outra* / Poço ou nascente } \\
\text { fora da propriedade } \\
\text { 4- Carro-pipa } \\
\text { 5- Água da chuva armazenada } \\
\text { em cisterna } \\
\text { 6- Água da chuva armazenada } \\
\text { de outra forma } \\
\text { 7- Rios, açudes, lagos e iga- } \\
\text { rapés } \\
\text { 8- Outra } \\
\text { 9- Poço ou nascente na aldeia } \\
\text { 10- Poço ou nascente fora da } \\
\text { aldeia }\end{array}$ & - \\
\hline $\begin{array}{l}\text { Esgotamen- } \\
\text { to sanitário }\end{array}$ & $\begin{array}{l}\text { 1- Rede geral } \\
\text { de esgoto ou } \\
\text { pluvial }\end{array}$ & $\begin{array}{l}\text { 2- Fossa } \\
\text { séptica } \\
\text { 3- Fossa } \\
\text { rudimentar }\end{array}$ & $\begin{array}{l}\text { 4- Vala } \\
\text { 5- Rio, lago ou mar } \\
\text { 6- Outro escoadouro }\end{array}$ & - \\
\hline $\begin{array}{l}\text { Abasteci- } \\
\text { mento de } \\
\text { energia elé- } \\
\text { trica }\end{array}$ & $\begin{array}{l}\text { 1- Sim* / Sim, } \\
\text { de companhia } \\
\text { distribuidora } \\
\text { 2- Sim, de } \\
\text { outras fontes }\end{array}$ & - & - & \begin{tabular}{|l|} 
2- Não* / \\
3- Não \\
existe \\
energia \\
elétrica
\end{tabular} \\
\hline
\end{tabular}

Obs.: As definições marcadas com * referem-se ao Censo 2000, as demais se mantiveram idênticas.

Fonte: IBGE (2002, 2012).

Elaborado pelos autores. 
A pesquisa considera como padrão adequado de acesso a infraestrutura quanto às variáveis em análise neste artigo, os domicílios onde havia acesso simultâneo ao abastecimento de água por rede geral, esgotamento sanitário por rede coletora (diretamente ou via fossa séptica ligada à rede) e abastecimento de energia elétrica. O padrão de acesso inadequado refere-se à forma como o acesso é feito, assim, situações de domicílios não conectados a redes gerais, seja de abastecimento de água e esgoto, e que obtêm água por poço ou nascente e têm a destinação final do esgoto por meio de fossa séptica ou fossa rudimentar. Já o padrão de acesso precário ocorre quando a água é acessada sem a identificação de sua fonte e o esgoto é despejado em valas, rios ou outro escoadouro. No Quadro 1 é possível observar que houve uma ampliação nos atributos para a variável abastecimento de água, enquanto em 2000 havia três, em 2010, devido ao avanço nas pesquisas do instituto, a mesma variável está sujeita a classificação em 10 atributos. Da mesma forma, observa-se que há modificação no Censo Demográfico de 2010 quanto à classificação dos atributos da variável abastecimento de energia elétrica que passa a contar com duas opções de resposta (1- Sim, de companhia distribuidora; 2- Sim, de outras fontes). Assim, embora tenha sido mantida a mesma classificação de acesso adequado, o padrão de acesso precário foi ampliado para incluir os itens não constantes do Censo 2000.

A simultaneidade nos acessos, aspecto básico na construção da metodologia de análise, está ligada aos conceitos de integração e conectividade de infraestrutura urbana sugeridos por Silva (2011). A integração pela existência de mais de um serviço de saneamento leva a um aprofundamento da análise quanto à localização, concentração e dispersão das redes no espaço intraurbano dos municípios amazônicos. Apesar de reconhecer a dificuldade na análise em função da inexistência de informação e de limitações no processamento das poucas existentes, a integração é uma questão-chave no planejamento e manutenção de recursos hídricos, particularmente em áreas urbanas. $\mathrm{O}$ autor alerta que apenas $\mathrm{O}$ acesso a pelo menos um serviço básico, precipuamente ao abastecimento de água por rede geral, conduz à tendência na diminuição da importância da dimensão estratégica do controle social sobre a provisão dos serviços, uma vez que a localização específica de concentrações privilegiadas de quantidade e qualidade de serviços revelam padrões de segregação socioespacial.

Trata-se de interferências no ciclo natural da água em áreas urbanas, já que tanto o fornecimento de água como o sistema de esgotamento sanitário compõem 
o mesmo ciclo hídrico. $\mathrm{O}$ autor mostra que a robustez e a resiliência na prestação de serviços de água dependem de uma performance integrada e conectada conjunta das funções de gestão em detrimento do funcionamento isolado. De fato, as áreas de baixa cobertura de conectividade de infraestrutura têm maior fragilidade ambiental, são as periferias urbanas, onde camadas populacionais mais sofrem com intermitência e ineficácia na cobertura dos serviços (SILVA, 2011, p. 92).

Com o objetivo de qualificar a variável "número de domicílios" de forma que pudesse expressar a condição da infraestrutura dos domicílios, tanto em termos de adequação e precariedade, como de conectividade, os atributos do Quadro 1 foram agrupados em 6 tipos (classes) de infraestrutura por meio do processo de mapeamento dos atributos das variáveis para os Censos 2000 e 2010, os quais compõem de forma resumida o Quadro 2 e são detalhados a seguir.

Quadro 2 - Descrição das classes de infraestrutura para qualificação de moradias mapeadas nos Censos Demográficos 2000 e 2010

\begin{tabular}{|l|l|}
\hline $\begin{array}{c}\text { Tipo de } \\
\text { infraestrutura }\end{array}$ & \multicolumn{1}{|c|}{ Definição } \\
\hline Moradia tipo 1 & $\begin{array}{l}\text { Melhor infraestrutura com acessos a três serviços básicos adequados } \\
\text { e disponíveis }\end{array}$ \\
\hline Moradia tipo 2 & $\begin{array}{l}\text { Dois serviços básicos têm acessos adequados e a um serviço básico } \\
\text { é inadequado }\end{array}$ \\
\hline Moradia tipo 3 & Um serviço básico tem acesso adequado e dois são inadequados \\
\hline Moradia tipo 4 & $\begin{array}{l}\text { Independentemente da existência de abastecimento de energia } \\
\text { elétrica, há pelo menos um serviço básico com acesso precário ou } \\
\text { inexistente }\end{array}$ \\
\hline Moradia tipo 5 & $\begin{array}{l}\text { Independentemente da existência de abastecimento de energia } \\
\text { elétrica, há pelo menos dois serviços básicos com acessos precários } \\
\text { ou inexistentes }\end{array}$ \\
\hline Moradia tipo 6 & Todos os serviços básicos têm acessos inadequados ou precários \\
\hline
\end{tabular}

Fonte: IBGE (2002, 2012).

Elaborado pelos autores.

Conforme assinalado, o Censo Demográfico de 2010 passou a incluir duas opções sobre a fonte do abastecimento de energia elétrica. Para os efeitos de análise, neste trabalho, foram mantidos os atributos de 2000, quanto à existência ou não do serviço, por se acreditar que no conjunto dos serviços básicos é evidente uma independência deste serviço em relação aos demais analisados. Daí a construção de tipos com este serviço isolado dos demais, mas que foi incluído pelas razões acima citadas. 


\section{METODOLOGIA APLICADA}

Este trabalho é baseado no uso de medidas de análise regional, amplamente utilizadas na literatura econômica como ferramenta metodológica para o estudo e a compreensão de fenômenos espaciais em diferentes escalas territoriais (local, regional e nacional), cujas referências podem ser encontradas entre outros, nos trabalhos de Suzigan et al. (2003), Crocco et al. (2006), Haddad (1989), Krugman (1991), Delgado e Godinho (2011), Florence (1948), Isard (1960), Monastério (2011) e Simões (2005). São medidas empregadas em estudos de natureza exploratória, calculadas a partir da distribuição espacial de uma determinada variável, tendo como abrangência diferentes dimensões de análise (localização espacial, especialização e concentração) e incorporando métodos e técnicas específicas de processamento.

Neste estudo, são utilizados índices de localização, especialização e de concentração, calculados para a provisão de infraestruturas no interior dos municípios, com o propósito de identificar e avaliar padrões municipais de conectividade de redes infraestruturais. Os padrões regionais de ocorrência da cobertura de infraestrutura foram definidos em função do mapeamento e da qualificação dos atributos das três variáveis selecionadas, isoladas ou em conjunto e considerando as condições de precariedade.

\subsection{BASE DE DADOS E TRATAMENTO DAS VARIÁVEIS SELECIONADAS}

As estatísticas descritivas e os índices analisados foram calculados a partir de variáveis extraídas de microdados ${ }^{2}$ da base de dados dos Censos Demográficos de 2000 e de 2010, coletadas e organizadas pelo IBGE. O cálculo dos indicadores requereu a escolha de uma variável consistente com a abordagem metodológica adotada e que fosse capaz de expressar e qualificar territorialmente o padrão espacial dos domicílios urbanos.

Além da variável de aferição do fenômeno (número de domicílios), a metodologia para o cálculo dos índices de análise regional requer que se estabeleçam valores que possam ser desgredados/distribuídos por classes ou categorias e por unidades territoriais, neste caso, os municípios. Dessa forma, a

2 As bases de microdados da amostra dos Censos Demográficos são disponibilizadas para aquisição no site do IBGE (IBGE, s.d.). 
construção das classes envolveu o mapeamento dos atributos dos três serviços básicos de infraestrutura dos domicílios investigados pelos censos do ano de 2000 e 2010: abastecimento de água, existência de esgotamento sanitário e fornecimento de energia elétrica. A relação das variáveis selecionadas e os respectivos atributos são relacionados conforme as combinações de atributos e qualificação conforme condições de adequação/inadequação, precariedade e inexistência de acesso serviços e classificado em tipos conforme a simultaneidade ou não com que os serviços são acessados, conforme visto no Quadro 3. No mesmo quadro são mostradas as alterações entre os dois censos, nos itens dos quesitos relativos ao atendimento do domicílio por rede geral de abastecimento de água e ao atendimento por energia elétrica. Sendo assim, a tarefa de mapeamento e qualificação dos atributos das três variáveis consideram tais alterações tendo em vista permitir a estratificação das classes de domicílios e a compatibilidade de análise entre as duas bases do Censo.

O quantitativo de municípios brasileiros em 2000 e em 2010 foi compatibilizado, identificando-se a criação de novos em função de desmembramentos, a fim de permitir compatibilizar informações e analisar comparativamente os índices relativos a uma mesma base territorial nos períodos de referência avaliados. Com esse propósito, recorreu-se ao uso da técnica de Áreas Mínimas Comparáveis (AMC) (REIS; PIMENTEL; ALVARENGA, 2008) que permitiu estabelecer 5.507 áreas comparáveis para o Brasil e 759 para a Amazônia Legal, tanto para o ano de 2000 quanto para o ano de 2010.

A pesquisa do Censo Demográfico utiliza dois tipos de questionários para levantamento de informações das características dos domicílios e das pessoas. O questionário básico, contendo um conjunto reduzido de quesitos que é aplicado em todas as unidades domiciliares, exceto naquelas selecionadas por amostra, onde a investigação é mais detalhada e extensa, além de conter todas as variáveis do questionário básico, sendo aplicado nas unidades domiciliares selecionadas por amostragem. Nesse sentido, partiu-se da variável "número de domicílios urbanos", obtido nas pesquisas do Censo Demográfico através do segundo questionário. 
Quadro 3 - Descrição das classes de moradia de domicílios urbanos com base no mapeamento dos atributos das variáveis dos Censos Demográficos 2000 e 2010

\begin{tabular}{|c|c|c|c|c|c|c|c|c|}
\hline \multirow[b]{2}{*}{ Condição } & \multicolumn{3}{|c|}{2000} & \multicolumn{3}{|c|}{2010} & \multirow[b]{2}{*}{ Atributos/Qualificação } & \multirow[b]{2}{*}{ Tipo } \\
\hline & $\begin{array}{c}\text { V0213 } \\
\text { (energia) }\end{array}$ & \begin{tabular}{l|} 
V0207 \\
(água)
\end{tabular} & $\begin{array}{c}\text { V0211 } \\
\text { (esgoto) }\end{array}$ & $\begin{array}{c}\text { V0211 } \\
\text { (energia) }\end{array}$ & $\begin{array}{l}\text { V0208 } \\
\text { (água) }\end{array}$ & $\begin{array}{c}\text { V0207 } \\
\text { (esgoto) }\end{array}$ & & \\
\hline \multirow{34}{*}{ SE } & $=1$ & $=1$ & $=1$ & $=1$ & $=1$ & $=1$ & $\begin{array}{l}\text { Melhor infraestrutura com os três } \\
\text { serviços básicos de acesso } \\
\text { adequados e disponíveis }\end{array}$ & 1 \\
\hline & $=1$ & $=1$ & $=2$ & $=2$ & $=1$ & $=1$ & \multirow{3}{*}{$\begin{array}{l}\text { Dois serviços básicos têm acessos } \\
\text { adequados e um serviço básico é } \\
\text { inadequado }\end{array}$} & \multirow{3}{*}{2} \\
\hline & \multirow{2}{*}{$=1$} & \multirow{2}{*}{$=2$} & \multirow{2}{*}{$=1$} & $=1$ & $=1$ & $=2$ & & \\
\hline & & & & $=1$ & $=2$ & $=1$ & & \\
\hline & \multirow{4}{*}{$=1$} & \multirow{4}{*}{$=2$} & \multirow{4}{*}{$=2$} & $=1$ & $=2$ & $=2$ & \multirow{4}{*}{$\begin{array}{c}\text { Um serviço básico tem acesso } \\
\text { adequado e dois têm acesso } \\
\text { inadequado }\end{array}$} & \multirow{4}{*}{3} \\
\hline & & & & $=2$ & $=1$ & $=2$ & & \\
\hline & & & & $=2$ & $=2$ & $=1$ & & \\
\hline & & & & $=2$ & $=2$ & $=2$ & & \\
\hline & $=1$ & $<3$ & $>2$ & $<3$ & $<3$ & $>2$ & \multirow{6}{*}{$\begin{array}{l}\text { Independentemente da existência } \\
\text { de abastecimento de energia } \\
\text { elétrica, há pelo menos um serviço } \\
\text { básico com acesso precário ou } \\
\text { inexistente }\end{array}$} & \multirow{6}{*}{4} \\
\hline & $=1$ & $<3$ & Branco & $<3$ & $<3$ & Branco & & \\
\hline & $=1$ & $=3$ & $<3$ & $<3$ & $>2$ & $<3$ & & \\
\hline & $=1$ & Branco & $<3$ & $<3$ & Branco & $<3$ & & \\
\hline & $=2$ & $<3$ & $<3$ & $=3$ & $<3$ & $<3$ & & \\
\hline & Branco & $<3$ & $<3$ & Branco & $<3$ & $<3$ & & \\
\hline & $=1$ & $=3$ & $>2$ & $<3$ & $>2$ & $>2$ & \multirow{12}{*}{$\begin{array}{l}\text { Independentemente da existência } \\
\text { de abastecimento de energia } \\
\text { elétrica, há pelo menos dois } \\
\text { serviços básicos com acesso } \\
\text { precário ou inexistentes }\end{array}$} & \multirow{12}{*}{ Tipo 5} \\
\hline & $=1$ & $=3$ & Branco & $<3$ & $>2$ & Branco & & \\
\hline & $=1$ & Branco & $>2$ & $<3$ & Branco & $>2$ & & \\
\hline & $=1$ & Branco & Branco & $<3$ & Branco & Branco & & \\
\hline & $=2$ & \begin{tabular}{|l|}
$<3$ \\
\end{tabular} & $>2$ & $=3$ & $<3$ & $>2$ & & \\
\hline & $=2$ & $<3$ & Branco & $=3$ & $<3$ & Branco & & \\
\hline & $=2$ & $=3$ & $<3$ & $=3$ & $>2$ & $<3$ & & \\
\hline & $=2$ & Branco & $<3$ & $=3$ & Branco & $<3$ & & \\
\hline & Branco & $<3$ & $>2$ & Branco & $<3$ & $>2$ & & \\
\hline & Branco & $<3$ & Branco & Branco & $<3$ & Branco & & \\
\hline & Branco & $=3$ & $<3$ & Branco & $>2$ & $<3$ & & \\
\hline & Branco & Branco & $<3$ & Branco & Branco & $<3$ & & \\
\hline & $=2$ & $=3$ & $>2$ & $=3$ & $>2$ & $>2$ & \multirow{8}{*}{$\begin{array}{l}\text { Todos os serviços básicos têm } \\
\text { acesso inadequado, precário ou } \\
\text { inexistente }\end{array}$} & \multirow{8}{*}{ Tipo 6} \\
\hline & $=2$ & $=3$ & Branco & $=3$ & $>2$ & Branco & & \\
\hline & $=2$ & Branco & $>2$ & $=3$ & Branco & $>2$ & & \\
\hline & $=2$ & Branco & Branco & $=3$ & Branco & Branco & & \\
\hline & Branco & $=3$ & $>2$ & Branco & $>2$ & $>2$ & & \\
\hline & Branco & $=3$ & Branco & Branco & $>2$ & Branco & & \\
\hline & Branco & Branco & $>2$ & Branco & Branco & $>2$ & & \\
\hline & Branco & Branco & Branco & Branco & Branco & Branco & & \\
\hline
\end{tabular}

Fonte: IBGE $(2002,2012)$.

Elaborado pelos autores.

\section{ANÁLISES E DISCUSSÃO DOS RESULTADOS}

\subsection{PADRÕES DE PROVISÃO DE INFRAESTRUTURA NO UNIVERSO DA PESQUISA}

O universo dos dados que foram tratados e processados envolveu um número significativo de informações das variáveis sumariadas, conforme os 
respectivos atributos, abrangendo todos os municípios do país. Os inputs para o processamento dos índices foram formados pelas informações do domicílio (x), classificadas em urbanas e agrupadas em 6 classes (k) de infraestrutura (Quadro 3), tendo como recorte territorial de análise os municípios brasileiros e, como espaço temporal analítico, os anos de 2000 e de 2010. A Tabela 1 mostra a totalização e a classificação inicial do número de municípios em cada uma das classes.

Embora o número total de domicílios pesquisados tenha-se ampliado entre 2000 e 2010, verifica-se, nos municípios da Amazônia Legal, que pouco se alterou a proporção do número de domicílios urbanos com infraestrutura do tipo 1 (aqueles que são atendidos com serviços básicos de abastecimento de água, fornecimento de energia elétrica e esgotamento sanitário). No Censo Demográfico de 2000, os domicílios do tipo 1 representavam apenas 13,2\% e, após uma década, somente $16,7 \%$ do total de domicílios urbanos na região, o que reflete uma participação de menos de 3\% do total de domicílios brasileiros.

A maioria dos domić́lios urbanos na Amazônia Legal, diferentemente do observado no Brasil, possui condição de moradia do tipo 4, no qual o acesso a dois serviços básicos é bom ou minimamente adequado e um terceiro tem acesso inadequado, precário ou mesmo inexistente. $\mathrm{O}$ percentual de domicílios urbanos com infraestrutura do tipo 4 era 49,6\% no Censo Demográfico de 2000 e atingiu 55,8\% no de 2010; nos demais municípios do Brasil, houve uma pequena queda no percentual de domicílios urbanos com esse padrão de moradia, passando de 25,2\% para 23,5. Concorre para tais diferenças, o maior número de domić́lios urbanos atendidos com fornecimento de energia elétrica, que saltou de 3,1 milhões no Censo Demográfico de 2000 para 4,6 milhões de domicílios no de 2010, valores muito próximos do universo de domicílios recenseados na Amazônia Legal. O atendimento com esse serviço atingiu então 97,1\% do total de domicílios urbanos. Os domicílios atendidos com abastecimento de água e esgotamento sanitário também tiveram crescimento, porém com uma variação absoluta menor. A situação mais precária verifica-se em relação ao número de domićlios atendidos com esgotamento sanitário, 904 mil em 2010, o que representa apenas 19,14\% dos domicílios urbanos pesquisados. Essa deficiência observada isoladamente na provisão dos três serviços básicos mostra que há claramente, nos termos apresentados por Silva (2011), um problema de conectividade nos sistemas infraestruturais nos municípios da região amazônica. Por outro lado, o número absoluto e relativo de domić́lios urbanos do tipo 6 (no qual todos os acessos aos serviços básicos são inadequados, precários ou inexistentes), apresentou um leve recuo no período, mantendo-se em torno de 1\% no Brasil e passando de 1,0\% para 1,9\% na Amazônia Legal. 


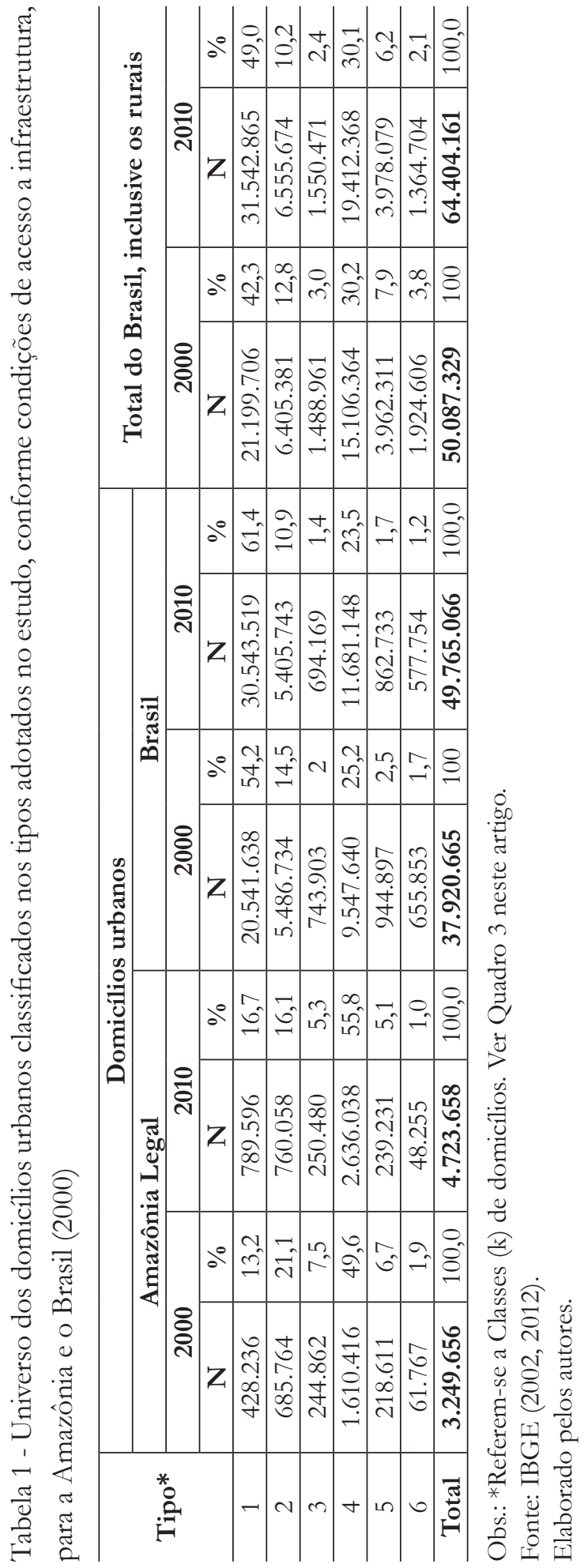


Assim, embora os dados do Censo Demográfico de 2010 indiquem alguns avanços na melhoria infraestrutural, quando comparados com os dados do recenseamento de 2000, constata-se que mais de 38\% dos domicílios urbanos no Brasil ainda não possuem acesso adequado a serviços básicos. Quando se levam em consideração apenas os municípios da Amazônia Legal, esse número representa mais de $80 \%$, revelando a situação extrema das condições de moradia da população dessa região, o que revela a tendência a capilarização da cobertura ocorrer em um momento de grande contração dos investimentos públicos nas capacidades centrais de gestão. Porém, o acesso desigual à infraestrutura pública é característico das baixas quantidade e qualidade dos serviços destinados às periferias pobres do que pela predominância de domicílios totalmente desconectados.

\subsection{PADRÃO DE LOCALIZAÇÃO DAS CONDIÇÕES DE MORADIA SEGUNDO O ACESSO À INFRAESTRUTURA}

A análise do Coeficiente de Gini Locacional (GL) permite mapear a distribuição espacial das classes (tipos de infraestrutura) sob análise em uma determinada área geográfica (SUZIGAN et al., 2003). O coeficiente foi processado para cada uma das seis classes de infraestrutura de moradia, tanto para os municípios do Brasil, como para os municípios da Amazônia Legal, a fim de permitir a comparação entre esses dois espaços geográficos, uma vez que o padrão de localização (distribuição) nacional não necessariamente representa o padrão de distribuição regional. A Tabela 2 apresenta os resultados do GL apurados para as classes de infraestrutura de domicílios urbanos nos anos de 2000 e de 2010. Eles expressam quão concentradas estão as classes de infraestrutura nos municípios do Brasil e nos da Amazônia Legal.

Tabela 2 - Coeficiente de Gini Locacional (GL) e Coeficiente de Reestruturação Setorial (CR) de acesso à infraestrutura, domicílios urbanos na Amazônia Legal e no Brasil (2000 e 2010)

\begin{tabular}{|c|c|c|c|c|c|c|}
\hline \multirow{3}{*}{$\begin{array}{c}\text { Classes de acesso à } \\
\text { infraestrutura para } \\
\text { moradia urbana }\end{array}$} & \multicolumn{3}{|c|}{ Amazônia Legal } & \multicolumn{3}{|c|}{ Brasil } \\
\hline & \multicolumn{2}{|c|}{$\begin{array}{c}\text { Gini } \\
\text { Locacional }\end{array}$} & \multirow{2}{*}{$\begin{array}{c}\text { CR } \\
2000 / 2010\end{array}$} & \multicolumn{2}{|c|}{$\begin{array}{c}\text { Gini } \\
\text { Locacional }\end{array}$} & \multirow{2}{*}{$\frac{\text { CR }}{2000 / 2010}$} \\
\hline & 2000 & 2010 & & 2000 & 2010 & \\
\hline Tipo 1 & 0,61 & 0,56 & 0,08 & 0,34 & 0,29 & 0,04 \\
\hline Tipo 2 & 0,41 & 0,35 & 0,12 & 0,59 & 0,57 & 0,13 \\
\hline Tipo 3 & 0,63 & 0,60 & 0,13 & 0,80 & 0,78 & 0,14 \\
\hline Tipo 4 & 0,27 & 0,23 & 0,07 & 0,52 & 0,54 & 0,08 \\
\hline Tipo 5 & 0,42 & 0,49 & 0,12 & 0,70 & 0,69 & 0,16 \\
\hline Tipo 6 & 0,39 & 0,38 & 0,15 & 0,31 & 0,37 & 0,11 \\
\hline
\end{tabular}

Fonte: IBGE (2002, 2012).

Elaborado pelos autores. 
Os escores de GL indicam que, tanto em 2000 como em 2010, nos municípios da Amazônia Legal, os domicílios com melhor infraestrutura de serviços básicos (tipo 1) são os mais concentrados geograficamente; consequentemente apresentam um padrão desigual de distribuição espacial na região. Já os domićlilios do tipo 4 (que reúne pelo menos dois serviços básicos minimamente adequados) estão mais uniformemente distribuídos no universo domiciliar amazônico. A expressão cartográfica da concentração é fornecida quando da análise (a seguir) do índice de concentração normalizado (ICn).

Observa-se ainda que o padrão de concentração dos domicílios urbanos do tipo 1 nos municípios da Amazônia Legal é bem superior ao verificado nos demais municípios brasileiros, uma vez que, na comparação com o índice gerado para o Brasil, em 2000, o GL indicava 0,61 contra 0,34 e, no ano de 2010, registrou 0,56 ante 0,29 (Tabela 2). Além disso, os escores baixos do coeficiente de reestruturação setorial (CR) sinalizam no sentido de que não houve mudanças substanciais nas características infraestruturais dos domicílios, o que significa que o padrão de provisão dos serviços básicos que atende os domićlios urbanos pouco se alterou no Brasil no intervalo de uma década.

\subsection{PADRÃO DE ESPECIALIZAÇÃO DAS CONDIÇÕES DE MORADIA}

O Índice de Especialização de Krugman (IK) permite avaliar quão especializados (ou diversificados) são os municípios, em termos de tipos de infraestrutura, em relação à unidade espacial de referência - neste caso, a totalidade dos municípios brasileiros. Os escores do IK (com intervalo de variação entre 0 e 2) para os 20 municípios da Amazônia Legal com maior e menor grau de especialização (diversificação) estão relacionados na Tabela 3, capaz de produzir uma aproximação à situação referente à provisão infraestrutural no município.

O município de Cuiabá (MT) destaca-se pelo maior padrão de diversidade $(\mathrm{IK}=0,12)$, ou seja, os 6 tipos de infraestrutura estão mais bem distribuídos entre os domicílios urbanos dessa unidade territorial. No entanto, essa melhor distribuição não significa que não exista desigualdade, visto que $51 \%$ dos domicílios urbanos do município possuem infraestrutura do tipo 1 (melhor disponibilidade de serviço básico) e, em 49\% dos domicílios urbanos, há diversidade dos demais tipos com serviços básicos parcialmente providos.

Entre os 20 municípios de maior diversidade também se observa a presença de algumas capitais regionais: São Luís (MA), Manaus (AM), Rio Branco (AC), Belém (PA) e Palmas (TO). Os valores do índice menor para esses municípios, em termos de atendimento de serviços básicos, são próximos dos escores 
observados para a estrutura dos domicílios das capitais nacionais. Isso quer dizer que, no geral, essas unidades territoriais apresentam uma composição de tipos de infraestrutura mais bem distribuídos (provisão diversificada) entre os seus domicílios urbanos, o que de certa forma já era esperado, uma vez que o maior número de domicílios tende a se concentrar em áreas urbanas mais densamente povoadas, mas isso não quer dizer que a disponibilidade de serviços seja melhor que em outras localidades.

Tabela 3 - Índice de Especialização de Krugman (IK) relativo aos tipos de infraestrutura, domicílios urbanos em municípios mais e os menos diversificados da Amazônia Legal (2000)

\begin{tabular}{c|c|c|c|c}
\hline Ord. & $\begin{array}{c}\text { Municípios mais } \\
\text { diversificados }\end{array}$ & IK & $\begin{array}{c}\text { Municípios menos } \\
\text { diversificados }\end{array}$ & IK \\
\hline $1^{\circ}$ & Cuiabá (MT) & 0,12 & Brejo de Areia (MA) & 1,91 \\
\hline $2^{\circ}$ & São Luís (MA) & 0,38 & Lagoa Grande do Maranhão (MA) & 1,79 \\
\hline $3^{\circ}$ & Barra do Garças (MT) & 0,42 & Cachoeira Grande (MA) & 1,64 \\
\hline $4^{\circ}$ & Guiratinga (MT) & 0,44 & Itaipava do Grajaú (MA) & 1,47 \\
\hline $5^{\circ}$ & Manaus (AM) & 0,50 & Ministro Andreazza (RO) & 1,46 \\
\hline $6^{\circ}$ & Rio Branco (AC) & 0,55 & Teixeirópolis (RO) & 1,46 \\
\hline $7^{\circ}$ & Coari (AM) & 0,57 & Indiavaí (MT) & 1,46 \\
\hline $8^{\circ}$ & Alto Araguaia (MT) & 0,61 & Campos de Júlio (MT) & 1,45 \\
\hline $9^{\circ}$ & Imperatriz (MA) & 0,63 & Novo Progresso (PA) & 1,45 \\
\hline $10^{\circ}$ & Caracaraí (RR) & 0,66 & Vale do Paraíso (RO) & 1,45 \\
\hline $11^{\circ}$ & Rondonópolis (MT) & 0,66 & Rio Sono (TO) & 1,45 \\
\hline $12^{\circ}$ & Serra do Navio (AP) & 0,67 & Sta. Terezinha do Tocantins (TO) & 1,45 \\
\hline $13^{\circ}$ & Pedreiras (MA) & 0,68 & Araguainha (MT) & 1,45 \\
\hline $14^{\circ}$ & Xapuri (AC) & 0,71 & Rio Crespo (RO) & 1,45 \\
\hline $15^{\circ}$ & Belém (PA) & 0,73 & Lavandeira (TO & 1,45 \\
\hline $16^{\circ}$ & Palmas (TO) & 0,75 & Ipueiras (TO) & 1,45 \\
\hline $17^{\circ}$ & Torixoréu (MT) & 0,77 & Sandolândia (TO) & 1,45 \\
\hline $18^{\circ}$ & Cáceres MT) & 0,81 & Governador Edison Lobão (MA) & 1,44 \\
\hline $19^{\circ}$ & Parauapebas (PA) & 0,82 & Ribeirãozinho (MT) & 1,44 \\
\hline $20^{\circ}$ & Mirassol d’Oeste (MT) & 0,84 & Buritirana (MA) & 1,44 \\
\hline & & & & \\
\hline & & & & \\
\hline & & & & \\
\hline
\end{tabular}

Fonte: IBGE (2002).

Elaborado pelos autores.

Entre os 100 municípios com melhor escore do IK, estão os dos estados do Pará (24) e do Amazonas (22), enquanto o do Tocantins reúne o maior número de municípios (41) com elevado padrão de especialização, isto é, concentram a maior parte de seus domicílios em uma única classe de infraestrutura de serviços básicos. 
Dos 20 municípios com elevado escore de IK, os quatro primeiros são do estado do Maranhão, e a composição dos tipos de infraestrutura de seus domicílios está mais distante da estrutura-base de comparação (Brasil). É o caso do município de Brejo de Areia (MA), que registrou maior IK (1,91), tendo 95\% dos seus domicílios com infraestrutura do tipo 5, ou seja, com apenas um serviço básico minimamente adequado.

Os resultados do IK para os municípios mais e os menos diversificados da Amazônia Legal relativos aos dados do Censo Demográfico de 2010 são apresentados na Tabela 4, e os valores do CR, que mede alterações no perfil de especialização do município entre 2000 e 2010, são apresentados na Tabela 5.

Tabela 4 - Índice de Especialização de Krugman (IK) relativo aos tipos de infraestrutura, domicílios urbanos em municípios mais e os menos diversificados da Amazônia Legal (2010)

\begin{tabular}{c|l|c|l|c}
\hline Ord. & \multicolumn{1}{|c|}{$\begin{array}{c}\text { Municípios mais } \\
\text { diversificados }\end{array}$} & IK & \multicolumn{1}{|c}{$\begin{array}{c}\text { Municípios menos } \\
\text { diversificados }\end{array}$} & IK \\
\hline $1^{\circ}$ & Guiratinga (MT) & 0,18 & Tupiratins (TO) & 1,66 \\
\hline $2^{\circ}$ & Cuiabá (MT) & 0,24 & São Félix do Tocantins (TO) & 1,66 \\
\hline $3^{\circ}$ & Serra do Navio (AP) & 0,26 & Chapada da Natividade (TO) & 1,66 \\
\hline $4^{\circ}$ & Caracaraí (RR) & 0,30 & Ipueiras (TO) & 1,63 \\
\hline $5^{\circ}$ & Cacoal (RO) & 0,30 & São Félix de Balsas (MA) & 1,59 \\
\hline $6^{\circ}$ & Porto Nacional (TO) & 0,36 & Careiro da Várzea (AM) & 1,53 \\
\hline $7^{\circ}$ & Barra do Garças (MT) & 0,37 & Lizarda (TO) & 1,53 \\
\hline $8^{\circ}$ & São Luís (MA) & 0,37 & Nova Rosalândia (TO) & 1,52 \\
\hline $9^{\circ}$ & Alvorada D’Oeste (RO) & 0,37 & Satubinha (MA) & 1,51 \\
\hline $10^{\circ}$ & Presidente Figueiredo (AM) & 0,39 & Ponte Branca (MA) & 1,51 \\
\hline $11^{\circ}$ & Talismã (TO) & 0,41 & Rio Crespo (RO) & 1,51 \\
\hline $12^{\circ}$ & Palmas (TO) & 0,42 & Joselândia (MA) & 1,50 \\
\hline $13^{\circ}$ & Iracema (RR) & 0,49 & Brasil Novo (PA) & 1,50 \\
\hline $14^{\circ}$ & Paço do Lumiar (MA) & 0,53 & Novo Horizonte do Oeste (RO) & 1,50 \\
\hline $15^{\circ}$ & Manaus (AM) & 0,54 & Vale do Paraíso (RO) & 1,50 \\
\hline $16^{\circ}$ & Imperatriz (MA) & 0,54 & Mirante da Serra (RO) & 1,50 \\
\hline $17^{\circ}$ & Darcinópolis (TO) & 0,58 & Pedro do Rosário (MA) & 1,50 \\
\hline $18^{\circ}$ & Belém (PA) & 0,59 & São José dos Basílios (MA) & 1,50 \\
\hline $19^{\circ}$ & Rio Branco (AC) & 0,63 & Bacurituba (MA) & 1,50 \\
\hline $20^{\circ}$ & Rondonópolis (MT) & 0,65 & Alto Taquari (MT) & 1,49 \\
\hline & & & \\
\hline & & & & \\
\hline
\end{tabular}

Fonte: IBGE (2012).

Elaborado pelos autores. 
A primeira observação a ser feita é que, assim como no ano de 2000, os principais centros urbanos da região também figuram em 2010 entre os municípios com provisão mais diversificada, com a presença de domicílios em todas as classes de infraestrutura e com um padrão relativamente mais próximo do padrão nacional. Dos 100 municípios com pior desempenho no IK, 31 são do estado do Maranhão e 25, do Tocantins.

Os valores do coeficiente de reestruturação (CR) confirmam que, na última década, houve pouca alteração no padrão de especialização da infraestrutura dos domicílios urbanos na região. Pode-se destacar entre as poucas mudanças o município de Ipueiras (TO), cujo maior valor do CR $(0,50)$ indica que houve uma alteração substancial no padrão de distribuição dos tipos de infraestrutura nessa localidade, uma vez que o IK aumentou de 1,45 para 1,63, entre 2000 e 2010. Em 2000, esse município tinha 73\% dos domicílios (naturalmente considerando apenas os dados do Censo Demográfico) com infraestrutura do tipo 4, ao passo que, em 2010, 87\% dos domicílios foram classificados com infraestrutura do tipo 2. Mas o resultado mostra que, apesar da maior especialização, a mudança foi positiva para as condições de moradia dos domicílios do município.

Tabela 5 - Maiores Coeficientes de Reestruturação (CR) relativos aos tipos de infraestrutura dos domicílios urbanos para os municípios da Amazônia Legal $(2000 / 2010)$

\begin{tabular}{c|l|c|c|l|c}
\hline Ordem & \multicolumn{1}{|c|}{ Municípios } & $\begin{array}{c}\text { CRi (2000/ } \\
\mathbf{2 0 1 0}\end{array}$ & Ordem & \multicolumn{1}{|c}{ Municípios } & $\begin{array}{c}\text { CRi (2000/ } \\
\mathbf{2 0 1 0}\end{array}$ \\
\hline $1^{\circ}$ & Ipueiras (TO) & 0,50 & $11^{\circ}$ & Mucajá́ (RR) & 0,39 \\
\hline $2^{\circ}$ & $\begin{array}{l}\text { Lagoa Grande do } \\
\text { Maranhão (MA) }\end{array}$ & 0,48 & $12^{\circ}$ & Tupiratins (TO) & 0,38 \\
\hline $3^{\circ}$ & $\begin{array}{l}\text { São Félix do } \\
\text { Tocantins (MA) }\end{array}$ & 0,46 & $13^{\circ}$ & $\begin{array}{l}\text { São Valério da Natividade } \\
\text { (TO) }\end{array}$ & 0,37 \\
\hline $4^{\circ}$ & $\begin{array}{l}\text { Chapada da } \\
\text { Natividade (TO) }\end{array}$ & 0,45 & $14^{\circ}$ & Lizarda (TO) & 0,36 \\
\hline $5^{\circ}$ & Amajari (RR) & 0,44 & $15^{\circ}$ & Taipas do Tocantins (TO) & 0,36 \\
\hline $6^{\circ}$ & $\begin{array}{l}\text { Itaipava do Grajaú } \\
\text { (MA) }\end{array}$ & 0,44 & $16^{\circ}$ & Porto Nacional (TO) & 0,34 \\
\hline $7^{\circ}$ & Acorizal (MT) & 0,41 & $17^{\circ}$ & Cantá (RR) & 0,33 \\
\hline $8^{\circ}$ & $\begin{array}{l}\text { Novo Progresso } \\
\text { (PA) }\end{array}$ & 0,40 & $18^{\circ}$ & Presidente Médici (MA) & 0,33 \\
\hline $9^{\circ}$ & $\begin{array}{l}\text { Careiro da Várzea } \\
\text { (AM) }\end{array}$ & 0,40 & $19^{\circ}$ & $\begin{array}{l}\text { São Raimundo do Doca } \\
\text { Bezerra (MA) }\end{array}$ & 0,32 \\
\hline $10^{\circ}$ & Ponte Branca (MT) & 0,39 & $20^{\circ}$ & Sucupira (TO) & 0,32 \\
\hline
\end{tabular}

Fonte: IBGE (2002, 2012).

Elaborado pelos autores. 


\subsection{PADRÃO DE CONCENTRAÇÃO DE DOMICÍLIOS SEGUNDO O ACESSO A INFRAESTRUTURA E CONDIÇÕES DE MORADIA NOS MUNICÍPIOS DA AMAZÔNIA LEGAL}

A análise do GL indicou que a maior concentração de domicílios se encontra nos tipos intermediários de infraestrutura de moradia, mas não localizou esses domicílios no território. Já o IK revelou que, no espaço amazônico, são os municípios com maior área urbana que, no geral, apresentam maior diversidade de tipos de infraestrutura de moradia. Com a análise do Índice de Concentração Normalizado (ICn), faz-se um refinamento dos resultados, o que aponta, para cada município, como estão distribuídos (concentrados) os tipos de infraestrutura dos domicílios urbanos, corroborando os resultados dos índices analisados anteriormente. O ICn foi calculado para cada um dos seis tipos de infraestrutura de moradia e em cada um dos municípios brasileiros, permitindo um exame comparativo das infraestruturas (Tabela 6).

A aplicação do indicador ICn permite constatar, de imediato, a expressiva desigualdade regional na provisão de serviços para os domicílios urbanos no país, refletida no padrão de concentração de cada um dos tipos de infraestrutura (Mapa 1). Para se ter uma ideia dessa disparidade, tomando como referência o Censo Demográfico de 2000, basta mencionar que, entre as 100 unidades territoriais que concentram domicílios com infraestrutura tipo 1, são listados apenas municípios de São Paulo e de Minas Gerais. No âmbito de suas estruturas urbanas, esses dois estados (São Paulo e Minas) apresentam domicílios com infraestrutura do tipo 1 distribuídos de maneira menos assimétrica entre seus municípios. Ampliando-se a lista para 500 municípios, verifica-se que apenas oito não pertencem a essas duas unidades da federação, nenhum deles está na Amazônia Legal e apenas três são da região Nordeste. 


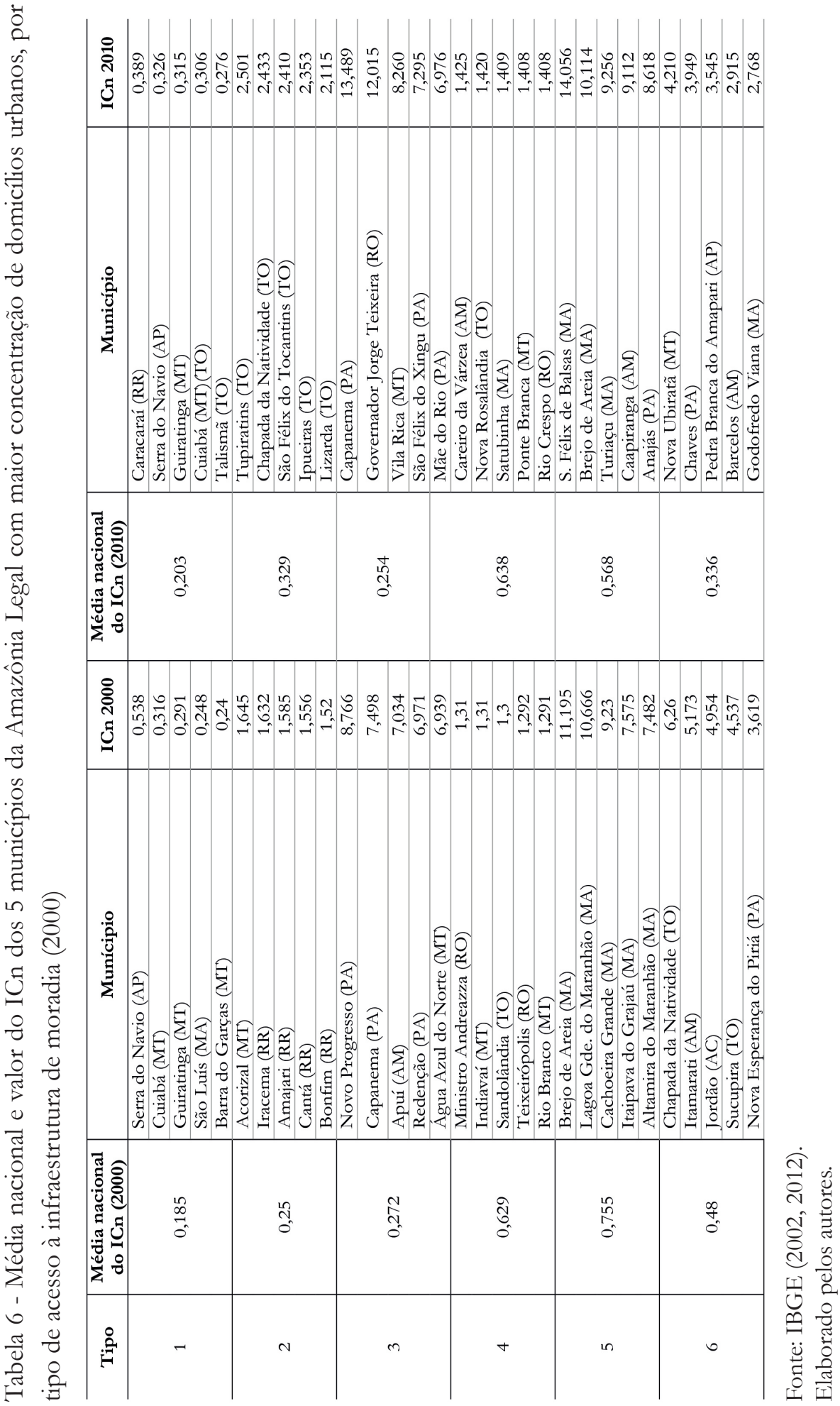


Inversamente, os 100 municípios que concentram domicilios com pior infraestrutura de moradia (tipo 6), situação em que os serviços básicos são inadequados, precários ou inexistentes, constata-se que 46 deles pertencem a estados da região Nordeste (sendo 50\% apenas no estado do Piau1), 29 situamse em estados da Amazônia Legal e apenas 9 são dos estados de São Paulo e de Minas Gerais. Essa disparidade em relação aos estados da região Sudeste aumenta à medida que se expande a lista de municípios. Esse quadro mantémse relativamente o mesmo em 2010, com municípios da região Sul e Sudeste concentrando os domicílios com melhor provisão de serviços básicos.

Quanto à Amazônia Legal, considerando os dois períodos sob análise, verifica-se que os domicílios com acesso a infraestrutura classificados no tipo 1 são menos concentrados em relação ao patamar médio dos domicílios brasileiros, medido pelo valor médio do ICn. Apenas 7 municípios com domicílios nessa condição estão acima da média nacional, entre os quais Serra do Navio (AP), que é o município da Amazônia Legal mais bem classificado entre os municípios brasileiros, ocupando a $655^{\underline{a}}$ posição no ranking nacional. O segundo município da Amazônia com infraestrutura do tipo 1 (Cuiabá-MT) aparece na 1640ํㅗ posição.

Em contraste, os ICn médios dos demais tipos (2 a 6) de infraestrutura dos domicílios na região são maiores que as médias dos índices para as infraestruturas dos domicílios nacionais. Isso significa que a Amazônia concentra poucos domicílios com condições adequadas de serviços básicos e ao mesmo tempo também agrega a maior proporção de domicílios com condições inadequadas, precárias ou insuficientes no que diz respeito à oferta dessa infraestrutura. Para a classificação dos níveis de concentração representados no Mapa 1, adotou-se a média e o desvio padrão nacional para cada tipo de infraestrutura; com base neles, foram adotados quatro níveis de corte satisfatórios para categorizar o $\mathrm{ICn}^{3}$.

Observa-se que no Censo Demográfico de 2000 apenas o município de Serra do Navio (AP) foi classificado na categoria "muito alta concentração", com valor do ICn muito superior ao da média nacional. Na condição de "alta concentração" - com valores do ICn situados logo acima da média -, foram classificados apenas 6 municípios, entre os quais Cuiabá (MT) e São Luís (MA), duas capitais regionais.

De acordo com os dados do Censo Demográfico de 2010, nenhum município teve ICn relacionado com "muito alta concentração", o que denota melhora na distribuição dos valores entre os municípios. Os 13 municípios que

\footnotetext{
Adotou-se como categorização do ICn os níveis de corte, a saber: muito baixa concentração (ICn $\leq$ Média - 1 x Desvio padrão); baixa concentração (ICn $\leq$ Média e $>$ Média -1 x Desvio padrão); alta concentração (ICn $>$ Média e $\leq$ Média +1 x Desvio padrão) e muito alta concentração (ICN > Média +1 x Desvio padrão).
} 
obtiveram maior ICn foram classificados com "alta concentração", três desses municípios tenho maior aglomeração urbana (Cuiabá-MT, São Luís-MA e Palmas-TO). Apesar de serem também grandes aglomerações urbanas, Belém (PA) e Manaus (AM) tiveram ICn abaixo da média nos dois períodos (2000 e 2010), sendo classificadas como "baixa concentração".

Mapa 1 - Índice de Concentração Normalizado de domicílios urbanos com acesso à infraestrutura conforme o padrão tipo 1 para municípios brasileiros (2010)

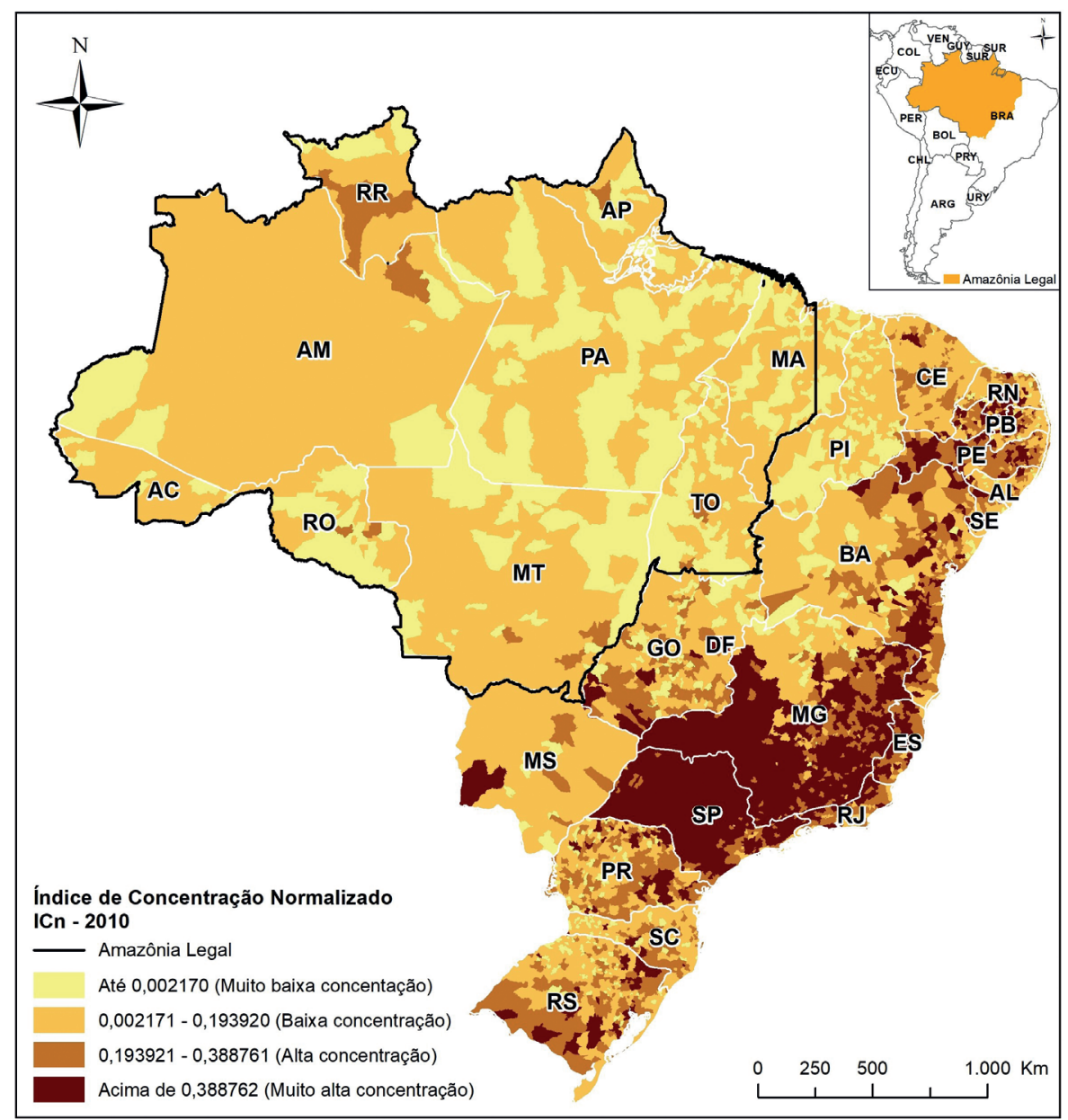

Fonte: IBGE (2012).

Elaborado pelos autores.

Nem mesmo os grandes centros urbanos da região apresentam um padrão de provisão de serviços básicos adequados, do ponto de vista de conectividade e da complementaridade, em seus domicílios (tipo 1). De fato, com exceção de Cuiabá 
(MT), as demais capitais apresentaram escores de ICn muito inferiores à média nacional (Tabela 7). Os dados do Censo Demográfico de 2000 mostraram que o município de Belém (PA), por exemplo, tinha seus domićlios concentrados, em sua maioria, nas infraestruturas dos tipos $2(\mathrm{ICn}=0,812)$ e $3(\mathrm{ICn}=2,221)$, que são apenas parcialmente adequadas. No Censo Demográfico de 2010, os valores do índice $(0,717$ e 1,854 , respectivamente) ainda indicavam uma relativa concentração nesses tipos. Listando-se os 100 municípios com pior provisão de infraestrutura (tipo 6), constata-se que 27 estão na Amazônia Legal (eram 29, em 2000).

Tabela 7 - Valor do ICn das capitais da Amazônia Legal, de acordo com a ordem de concentração de acesso à infraestrutura de tipo 1 e posição no ranking nacional (2000 e 2010)

\begin{tabular}{|c|c|c|c|c|c|c|c|c|}
\hline \multicolumn{9}{|c|}{ ICn (2000) } \\
\hline Ranking & UF & Município & Tipo 1 & Tipo 2 & Tipo 3 & Tipo 4 & Tipo 5 & Tipo 6 \\
\hline - & - & $\begin{array}{l}\text { ICn médio } \\
\text { das capitais }\end{array}$ & 0,283 & 0,473 & 0,570 & 0,328 & 0,277 & 0,299 \\
\hline $1640^{\circ}$ & MT & Cuiabá & 0,316 & 0,419 & 0,291 & 0,305 & 0,241 & 0,333 \\
\hline $1892^{\circ}$ & MA & São Luís & 0,248 & 0,221 & 0,192 & 0,490 & 1,220 & 0,189 \\
\hline $2104^{\circ}$ & $\mathrm{AM}$ & Manaus & 0,184 & 0,631 & 0,962 & 0,340 & 0,881 & 0,257 \\
\hline $2163^{\circ}$ & $\mathrm{AC}$ & Rio Branco & 0,169 & 0,347 & 0,688 & 0,594 & 0,718 & 0,153 \\
\hline $2310^{\circ}$ & PA & Belém & 0,134 & 0,812 & 2,221 & 0,301 & 0,296 & 0,162 \\
\hline $2410^{\circ}$ & TO & Palmas & 0,112 & 0,882 & 0,344 & 0,456 & 0,108 & 0,340 \\
\hline $2460^{\circ}$ & RR & Boa Vista & 0,099 & 1,249 & 0,095 & 0,279 & 0,057 & 0,213 \\
\hline $2819^{\circ}$ & $\mathrm{AP}$ & Macapá & 0,045 & 0,263 & 2,043 & 0,818 & 0,530 & 0,316 \\
\hline $2830^{\circ}$ & $\mathrm{RO}$ & Porto Velho & 0,044 & 0,501 & 5,622 & 0,418 & 0,241 & 0,166 \\
\hline \multicolumn{9}{|c|}{ ICn (2010) } \\
\hline Ranking & UF & Município & Tipo 1 & Tipo 2 & Tipo 3 & Tipo 4 & Tipo 5 & Tipo 6 \\
\hline - & - & $\begin{array}{l}\text { ICn médio } \\
\text { das capitais }\end{array}$ & 0,285 & 0,430 & 0,207 & 0,385 & 0,104 & 0,259 \\
\hline $1952^{\circ}$ & MT & Cuiabá & 0,306 & 0,598 & 0,269 & 0,248 & 0,213 & 0,547 \\
\hline $2289^{\circ}$ & $\mathrm{MA}$ & São Luís & 0,235 & 0,419 & 0,584 & 0,418 & 1,544 & 0,247 \\
\hline $2300^{\circ}$ & TO & Palmas & 0,232 & 0,689 & 0,119 & 0,428 & 0,039 & 0,276 \\
\hline $2472^{\circ}$ & $\mathrm{AM}$ & Manaus & 0,191 & 0,499 & 1,272 & 0,495 & 1,103 & 0,232 \\
\hline $2525^{\circ}$ & $\mathrm{PA}$ & Belém & 0,178 & 0,717 & 1,854 & 0,439 & 0,378 & 0,108 \\
\hline $2576^{\circ}$ & $\mathrm{AC}$ & Rio Branco & 0,166 & 0,612 & 1,365 & 0,523 & 0,626 & 0,193 \\
\hline $2896^{\circ}$ & RR & Boa Vista & 0,102 & 0,974 & 0,207 & 0,611 & 0,108 & 0,242 \\
\hline $3318^{\circ}$ & $\mathrm{AP}$ & Macapá & 0,043 & 0,272 & 2,185 & 0,974 & 0,536 & 0,401 \\
\hline $3365^{\circ}$ & RO & Porto Velho & 0,038 & 0,427 & 4,549 & 0,760 & 0,647 & 0,201 \\
\hline
\end{tabular}

Fonte: IBGE (2002, 2012).

Elaborado pelos autores.

Esses resultados demonstram que a Amazônia Legal, além de distanciar-se da média nacional, não apresentou, entre 2000 e 2010, uma evolução significativa no quadro de provisão de serviços básicos para moradia, o que corrobora os padrões de especialização obtidos pela análise do Coeficiente de Reestruturação, anteriormente apresentado. 
Quando se observam os escores de ICn do ano de 2000, calculados para os tipos de infraestrutura nos municípios das capitais na Amazônia Legal, constata-se uma discrepância em relação aos valores médios nacionais (Tabela 8). Cuiabá (MT) destaca-se por ser o município que concentra o maior número de domicílios com serviços adequados (tipo 1), com valores do ICn acima do patamar médio das capitais brasileiras, tanto em 2000 como em 2010, além de apresentar a melhor diversidade de infraestrutura medida pelo IK.

Entre 2000 e 2010, Palmas (TO), capital planejada criada em 1989, foi o município que apresentou a maior evolução no seu padrão de infraestrutura para moradia: elevou-se o grau de concentração dos domicílios com melhor infraestrutura (tipo 1), reduzindo-se, em contrapartida, a concentração de domicílios em todos os demais tipos e provisão de serviços. Já o município de Porto Velho (RO) ocupa a pior classificação entre as capitais da Amazônia, com grande parte de seus domicílios apresentando provisão de infraestrutura do tipo 3.

Manaus e Belém têm seus domicílios concentrados em classes intermediárias, com alguns serviços básicos precários ou até mesmo inexistentes. No caso de Belém, o valor do ICn registrado em ambos os períodos indica uma forte concentração de domicílios com infraestrutura do tipo 3, no qual existe apenas o acesso a um serviço minimamente adequado.

\section{CONSIDERAÇÕES FINAIS}

Embora os dados de 2010 tenham revelado alguns avanços na infraestrutura das condições de moradia dos domicílios da Amazônia Legal, a comparação com os dados de 2000 faz constatar que mais de $80 \%$ dos domicílios urbanos ainda não têm acesso adequado a serviços básicos, o que expõe a situação extrema da condição de vida da população na região. A disponibilidade dos serviços aqui estudados ainda está longe de ser ideal no Brasil, com menos de 50\% da população tendo acesso simultaneamente a esses três serviços por rede pública. Esse dado é inferior a 30\% quando se refere à Amazônia.

No intervalo de uma década, houve pouca alteração no padrão de distribuição espacial da provisão de serviços básicos para os domicílios urbanos brasileiros, com os estados de São Paulo e Minas Gerais mantendo a preponderância de municípios na aglomeração de domicílios com melhor acesso a esses serviços. Houve uma significativa redução no padrão de concentração, tanto no Brasil como na Amazônia, no que se refere à infraestrutura do tipo 6 com destaque para a evolução de programas sociais de ampliação do abastecimento de energia elétrica atribuída ao Programa Luz para Todos na Amazônia. 
Não se observou uma melhoria relativa substancial da posição da região em relação à média do Brasil quanto à provisão adequada dos serviços básicos para os domicílios urbanos. Os índices indicaram que, no geral, os domicílios urbanos da Amazônia Legal caracterizam-se pela provisão inadequada, precária ou mesmo inexistente de serviços básicos, o que é mais evidente nas grandes aglomerações urbanas. Entre os municípios sede das capitais, Cuiabá (MT) foi a que registrou a maior concentração de domicílios com provisão adequada de serviços básicos, e Palmas (TO), a cidade com melhor evolução infraestrutural no período.

Ao contrário do que ocorre nos municípios com melhor atendimento de serviços básicos no Brasil, onde praticamente inexiste concentração de domicílios com acesso do tipo mais precário, entre os municípios da Amazônia que têm melhor provisão de serviços básicos em seus domicílios, ainda é significativa a concentração de moradias com provisão inadequada, precária ou mesmo inexistente de serviços básicos.

\section{REFERÊNCIAS}

BECKER, B. Amazônia: mudanças estruturais e urbanização. In: GONÇALVES, M. F.; BRANDÃO, C. A.; GALVÃO, A. C. (org.). Regiões e cidades: o desafio urbano-regional. São Paulo: UNESP, 2003. p. 651-656.

BRASIL. Lei Federal $\mathbf{n}^{\mathbf{0}} \mathbf{5 . 1 7 3}$, de 27/10/1966. Dispõe sôbre o Plano de Valorização Econômica da Amazônia e dá outras providências. Brasília, DF: Presidência da República, [1966]. Disponível em: http://www.planalto.gov.br/ ccivil_03/leis/L5173.htm. Acesso em: 20 jun. 2020.

BRASIL. Lei $\mathbf{n}^{\mathbf{0}} \mathbf{1 1 . 4 4 5}$, de 5 de janeiro de 2007. Estabelece diretrizes nacionais para o saneamento básico [...]. Brasília, DF: Presidência da República, [2007]. Disponível em: http://www.planalto.gov.br/ccivil_03/_ato2007-2010/2007/ lei/111445.htm. Acesso em: 20 jun. 2020.

BRASIL. Ministério das Cidades. Panorama do Saneamento Básico no Brasil. Brasília, DF: MCIDADES, 2014.

BRITO, F. A.; PINHO, B. A. T. D. A dinâmica do processo de urbanização no Brasil, 1940-2010. Belo Horizonte: CEDEPLAR/UFMG, 2012. (Texto para discussão, n. 464). Disponível em: http://cedeplar.ufmg.br/pesquisas/td/ TD\%20464.pdf. Acesso em: 20 jun. 2020.

CANO, W. Desequilíbrios regionais e concentração industrial no Brasil: 
1930-1970. 3. ed. São Paulo: Editora da UNESP, 2007.

CASTRO, E. (org.). Cidades na floresta. São Paulo: Annablume, 2008.

CROCCO, M. A. et al. Metodologia de identificação de aglomerações produtivas locais. Nova Economia, Belo Horizonte, v. 16, n. 2, p. 211-241, maio/ago. 2006.

DELGADO, A. P.; GODINHO, I. M. C. Medidas de localização das actividades e de especialização regional. In: COSTA, J. S.; DENTINHO, T. P.; NIJKAMP, P. (coord.). Compêndio de economia regional: métodos e técnicas de análise regional. Cascais: Principia, 2011. p. 15-35. v. 2.

FLORENCE, P. S. Investment, location and size of plant: a realistic inquiry into the structure of British and American industries. Cambridge: Cambridge University Press, 1948.

HADDAD, P. R. Medidas de localização e de especialização. In: HADDAD, P. R. (org.). Economia regional: teorias e métodos de análise. Fortaleza: Banco do Nordeste do Brasil, 1989. p. 225-248.

IBGE. Censo demográfico 2000: microdados da amostra. Rio de Janeiro: IBGE, 2002. 1 CD-ROM.

IBGE. Pesquisa Nacional de Saneamento Básico - PNSB. IBGE, Rio de Janeiro, 2008. Disponível em: https://www.ibge.gov.br/estatisticas/multidominio/meioambiente/9073-pesquisa-nacional-de-saneamento-basico.html? =\&t=sobre. Acesso em: 20 jun. 2020.

IBGE. Censo demográfico 2010: microdados da amostra. Rio de Janeiro: IBGE, 2012. 1 CD-ROM.

IBGE. Censo demográfico: microdados. IBGE, Rio de Janeiro, s.d. Disponível em: https: / /www.ibge.gov.br/estatisticas/sociais/populacao/22827-censo-2020censo4.html? =\&t=microdados. Acesso em: 20 jun. 2020.

ISARD, W. Methods of regional analysis: an introduction to regional science. Cambridge: MIT Press, 1960.

KLEIMAN, M. Permanências de assimetrias em infraestrutura no desenvolvimento regional do Brasil. Chão Urbano, Rio de Janeiro, ano XV, n. 5, set./out. 2015. Disponível em: http://chaourbano.com.br/visualizarArtigo. php?id=98. Acesso em: 20 jun. 2020.

KRUGMAN, P. Geography and trade. Cambridge: MIT Press, 1991. 
MONASTERIO, L. Indicadores de análise regional e espacial. In: CRUZ, B. O. (org.). Economia regional e urbana: teorias e métodos com ênfase no Brasil. Brasília: Ipea, 2011. p. 315-331.

REIS, E.; PIMENTEL, M.; ALVARENGA, A. I. Áreas mínimas comparáveis para os períodos intercensitários de 1872 a 2000. Rio de Janeiro: Ipea/Dimac, 2008.

SILVA, R. T. Integration of hydraulic infrastructure in metropolitan São Paulo. Prospects of change in a context of growing vulnerability. Geographica Helvetica, [S. l.], v. 66-2, p. 92-99, 2011.

SILVA, R. T. A conectividade das redes de infra-estrutura e o espaço urbano de São Paulo. In: RIBEIRO, L. C. Q. (org). O futuro das metrópoles: desigualdades e governabilidade. 2. ed. Rio de Janeiro: Letra Capital, 2015. p. 407-432.

SIMÕES, R. F., Métodos de análise regional e urbana: diagnóstico aplicado ao planejamento. Belo Horizonte: CEDEPLAR/UFMG, 2005. (Texto para discussão, n. 259).

SUZIGAN, W. et al. Coeficiente de Gini locacionais - GL: aplicação à indústria de calçados do Estado de São Paulo. Nova Economia, [S. l.], v. 13, n. 2, p. 3960, 2003.

TRINDADE JÚNIOR, S-C. C. Cidades na floresta: os "grandes objetos" como expressões do meio técnico-científico informacional no espaço amazônico. Revista IEB, São Paulo, n. 51, p. 113-137, mar./set. 2010. 